\title{
Personalization of Web Browsing for Novice Users
}

\author{
Samudra Banerjee \\ Bachelor of Engineering, $7^{\text {th }}$ \\ Semester, \\ Department of Computer Science, \\ Birla Institute of Technology, \\ Mesra, India
}

\author{
Arindam Chatterjee \\ Bachelor of Engineering, $7^{\text {th }}$ \\ Semester, \\ Department of Information \\ Technology, \\ Birla Institute of Technology, \\ Mesra, India
}

\author{
Indrajit Mukherjee \\ Sr. Lecturer, \\ Department of Computer Science, \\ Birla Institute of Technology, Mesra, \\ India
}

\begin{abstract}
This paper discusses primary design issues of an intelligent browser for novice users. This work focuses on the study of intelligent interface agents which adapt to the user according to the interactions between the user and the browser. We propose a personal web browser which adapts to the user interface layout and navigation. Adaptation of user interface is associated with including both layout and functionality to the user's ability and preference but generally keeping consistency. Adaptation to navigation on the other hand refers to personalization of web pages so as to provide personalized information space.
\end{abstract}

\section{Categories and Subject Descriptors}

D.3.3 [Programming Languages]: Language Contructs and Features - abstract data types, polymorphism, control structures.

H.5.2 [User Interfaces (D.2.2, H.1.2, I.3.6)]: Ergonomics, Evaluation/methodology, Input devices and strategies (e.g., mouse, touchscreen), Interaction styles (e.g., commands, menus, forms, direct manipulation), Screen design (e.g., text, graphics, color), Theory and methods, Training, help, and documentation, User interface management systems (UIMS), Windowing systems

\section{General Terms}

Algorithms, Performance, Design, Experimentation, Languages.

\section{Keywords}

Web Browsing, Personalization, User Interface

\section{INTRODUCTION}

The World Wide Web opens the possibility for individuals to access information and interact with each other and with computers. However, despite the growing proportion of the population of computer literate and illiterate citizens in society, the population of computer illiterate Internet users is relatively very small. The reasons which have led to this situation could be complicated.

Research shows that the user model of computer illiterate in browsing the Web is quite different from regular users and they have difficulties using a normal browser [1] [2] [3]. Some of the suggestions are that they need simpler user interface and that

of more readable display: for example, bigger buttons, larger fonts, higher display contrasts, easier-to-use pointing devices.
Because of the rapid growth of Internet users, the information on the Web has been growing tremendously during the last several years, Even an experienced user can sometimes get lost when navigating. To cope with this growing problem, personalized webbased searching has attracted substantial research work and some promising results have been announced. For example, WBI [6] [7] is an implemented system that provides a loosely confederated group of agents on a user's workstation capable of observing user actions, proactively offering assistance, modifying resulting web documents, and performing new functions, BASAR [6] [7] is a web assistant providing user-specific help for browsing tasks based on a user, task and domain model. Both of them use agent programs that add their functions to the existing browser. Unfortunately, an inexperienced user may have some difficulties in dealing with a browser bundled with agents. We propose a browser with built-in intelligent functions to address the simplicity which is necessary for those types of users. The intelligence of the browser is based on the dynamic user model which is built by observing the discourse between the user and browser.

\section{GENERAL DESIGN CONSIDERATIONS}

Considerable progress has been made in adapting interactive software systems [10][11]. The key issue in providing useroriented adaptability is to acquire a personalized user model. One approach is to require the user to specify her preferences, but this approach is inappropriate for inexperienced users because they may not have the confidence to change the default setting at an early stage of using a system. An alternative is the stereotype approach [10] that is based on the research results on the general user model. This is feasible, but the general model may not be suitable for everybody and it can not be tailored to personal needs. Another powerful approach is to obtain a usage model by observing the user's interaction with the system as well as the information the user has obtained. The last approach can result in a personalized user model without requiring the active participation of the user. We are prototyping an easy browser with personalized information space by combining the three user model acquisition approaches. A basic general user model is built into the browser; the personalized model can be aggregated by observing the discourse; furthermore, the user is allowed to inspect and modify the model directly. The browser is designed to have the following features: 
- Adaptation of user interface including both layout and functionality to the user's ability and preference but generally keeping consistency.

- Adaptation of navigation to provide personalized information space.

\subsection{Adaptation of User Interface}

Because currently most of the users are not very experienced in Web searching, we put simplicity as our primary design consideration. The following principles are the guidelines to achieve this goal [12]: needed.

- Use progressive disclosure, hiding things until they are

\section{- Provide defaults}

We present the basic fundamentals first, and introduce necessary and more sophisticated functions gradually. For example, for a novice user, the simple browser can be provided with only "Back", "Forward", "Home" and "Stop" buttons. After the user becomes familiar with these basic navigating buttons, other functions like "Reload" and "Bookmark" functions can be added. Subsequently, "History List" and "Document Path" can be offered to the user for advanced browsing help.

\subsection{Adaptation of Personal Information Space}

Research on general user models for accessing the Web suggests that both experienced and inexperienced users think of the web as a physical space [7]. It also indicates that individuals focus on key nodes when recalling their searches and these key nodes help to structure memory [7]. Moreover, people tend to use the same search pattern over and over. Other research concludes that a Web user exploits bookmark as a personal information space [5]. The usage patterns of bookmark are the following:

- Starts small and build incrementally

- Selects only useful items

- Adds value through organization

- Manages with poor structure

- Establishes a personal view

Because novice users on the whole have more limited working processing memory and short term memory, it is important to reduce demands on working memory by providing external displays or notebook as much as possible [15]. Thus more functions for recalling the browsing history could be helpful. For example, if a novice user can retrieve the relevant documents by searching her browsing history by keywords, they may benefit from it. Moreover, the path of each document, which includes where they come from and where they have been can effectively help them in recognizing the trail of their searching. As a result of the important role of the bookmark in surfing the Web [5], bookmark default views are supplied according to the general interests of the novice. For example, some related information links are provided for the five most popular areas such as sports, the arts, genealogy, gardening and travel [Williamson 96]. In addition, the browser provides information on organizing and updating the bookmark depending on the usage model of the user.
For example, suggestions can be given to the user on deleting links which are not valid and less used as well as adding most recently visited pages to the bookmark. Furthermore, a hot list for the most frequently visited places is updated by the system automatically.

A new feature which can be included is web-page personalization. This means that for any URL, the user can modify the page according to her needs. When she visits the URL again, the modified page will be displayed. For instance, the user might feel that certain places in the web page are important and need to be highlighted. Our model of the personalized web browser will enable the user to do so. When she visits the URL again, the highlights will be visible. Our current model provides three personalization features

- $\quad$ Text Highlighting

- Text/Component Removal

- Text/Component Addition

Personalization feature is highly user specific. We propose to handle this feature by having a unique log in ID for each user. Every time a user wants to browse the web, she must log in. A central database will maintain her account details and every time she modifies a page, the changes are saved in the central database. All pages are accessed through the database and changes in a page(if any) are reflected.

\section{DESIGN, IMPLEMENTATION AND RESULT}

\subsection{Architecture}

The Architecture (Figure 1) of the browser is based on the Human Interaction . The User Interface Agent is designed to be the only one which interacts with the user. In other words, the user is unaware of the existence of any of the other agents assisting the browsing. The browser consists of the following components.

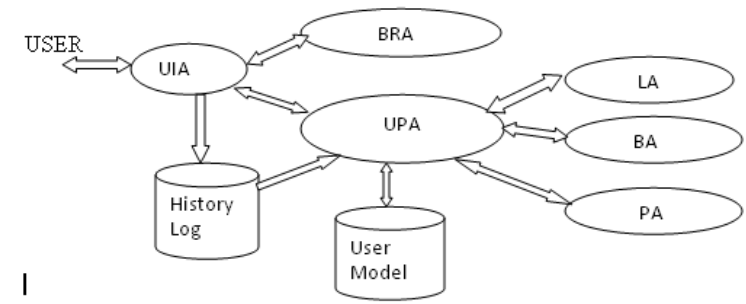

Figure 1. Architecture

- $\quad$ Browser Agent (BRA): provides the main browsing functions as a normal browser

- User Interface Agent (UIA): manipulates the active interfaces to the user according to the instructions from the user and UPA. It also records interactions of the user and information about browsing history to the respective log files.

- User Personalization Agent (UPA): instructs the UIA to adapt its active interface while managing and updating the user model by observing interactions between the user and UIA. It comprises several sub-agents to support the dynamic changes of the user model. 
- $\quad$ Bookmark Agent (BA): Handles bookmarks and hot lists of the user.

- Layout Agent (LA): Figures the suitable layout and functionality style of the browser for the user.

- $\quad$ Path Agent (PA): maintains the browsing history and clusters the trail of the user's visited links related to these visited pages.

- History log: Keeps the history of interactions between the user and the browser as well as information of the browsing history

- User model: Contains the system's assumptions about user preferences, capabilities, skills, knowledge and other factors, which are typically acquired by inductive processing based on observations about the user. It is deemed relevant for tailoring the interface of the browser to the user. It is updated dynamically according to the discourse between the user and the browser.

We propose to maintain the User Model and the History Log in a centralized database so that personalization is maintained irrespective of wherever the user is and which machine she uses.

\subsection{Algorithm}

The main concern of the UPA component is the dynamic nature of web pages. Information on the web is constantly updated, added and removed. The system should be efficient enough to work properly under these circumstances. Our algorithm for Text Highlighting is described below.

Whenever a user highlights a portion of the text, the starting and ending positions, along with the text are stored in the database. The algorithm to retrieve previous highlights is given below.

For each visit to page $\mathrm{P}$ having URL $\mathrm{U}$

begin

For each highlight entry against $U$,

begin

Retrieve the following from the database,

highlight start, HS

highlight end, HE

highlight text, HT

Five concepts prior to the highlighted text, $\mathrm{CP}$

Five concepts following the highlighted text, CF

Check if for the current page P, HS and HE enclose HT

If yes,

Highlight the text between HS and HE

If no,

begin

Start searching backwards from position, HS, in a thread, T1

Simultaneously start searching forward from position HE, in a thread, T2

For any of the above threads,

begin
If upper/lower limit of the page is reached,

if any match found, report values to Main thread

otherwise notify absence.

If text is found,

begin concepts.

check its preceding five concepts and following five

If match with $\mathrm{CP}$ and $\mathrm{CF}$ is greater than or equal to $90 \%$, report new values to Main Thread

stop

Otherwise,

Store percentage match, HS and HE

end

If text has been found by the other thread,

stop

end

If text is found by any of the threads,

begin

Of the two values obtained from the threads, choose the one with higher percentage match.

Highlight the text.

Update HS and HE.

end

end

end

Similar algorithm is used for retrieval of deleted and added Text/Components

3.3 Implementation and Experimental Results The first prototype of the browser was implemented using the Java language. The main interfacing objects of our implementation are listed below.

Table 1. Table captions should be placed above the table

\begin{tabular}{|c|c|c|c|c|}
\hline $\begin{array}{l}\text { Screen } \\
\text { Name }\end{array}$ & $\begin{array}{c}\text { Name of } \\
\text { Object } \\
\text { in UIA }\end{array}$ & Type & $\begin{array}{l}\text { Associated } \\
\text { Method in } \\
\text { UPA }\end{array}$ & Purpose \\
\hline $\begin{array}{l}\text { LoginScr } \\
\text { een }\end{array}$ & $\begin{array}{l}\text { User } \\
\text { Name }\end{array}$ & Textbox & & $\begin{array}{l}\text { To get the } \\
\text { user name } \\
\text { of the user }\end{array}$ \\
\hline $\begin{array}{l}\text { LoginScr } \\
\text { een }\end{array}$ & $\begin{array}{c}\text { Passwor } \\
\text { d }\end{array}$ & Password & & $\begin{array}{l}\text { To get the } \\
\text { password } \\
\text { for the co- } \\
\text { rrespondin } \\
\text { g account }\end{array}$ \\
\hline $\begin{array}{l}\text { LoginScr } \\
\text { een }\end{array}$ & Login & Button & $\begin{array}{l}\text { LoginActio } \\
\text { nPerformed } \\
\quad()\end{array}$ & $\begin{array}{l}\text { This } \\
\text { connects } \\
\text { the user to } \\
\text { his } \\
\text { account in } \\
\text { the }\end{array}$ \\
\hline
\end{tabular}




\begin{tabular}{|c|c|c|c|c|}
\hline & & & & $\begin{array}{c}\text { browser if } \\
\text { account is } \\
\text { valid }\end{array}$ \\
\hline $\begin{array}{l}\text { Browser } \\
\text { Scre-en }\end{array}$ & $\begin{array}{c}\text { Highligh } \\
\text { t }\end{array}$ & Button & $\begin{array}{l}\text { highlightAc } \\
\text { tionPerfor } \\
\text { med() }\end{array}$ & $\begin{array}{c}\text { It } \\
\text { highlights } \\
\text { the } \\
\text { selected } \\
\text { portion of } \\
\text { the page }\end{array}$ \\
\hline $\begin{array}{l}\text { Browser } \\
\text { Scre-en }\end{array}$ & Add & Button & $\begin{array}{l}\text { addActionP } \\
\text { erformed() }\end{array}$ & $\begin{array}{l}\text { It adds } \\
\text { contents } \\
\text { to the } \\
\text { page }\end{array}$ \\
\hline $\begin{array}{l}\text { Browser } \\
\text { Scre-en }\end{array}$ & Delete & Button & $\begin{array}{c}\text { deleteActio } \\
\text { nPerformed } \\
()\end{array}$ & $\begin{array}{l}\text { It deletes } \\
\text { the } \\
\text { selected } \\
\text { content of } \\
\text { the page }\end{array}$ \\
\hline $\begin{array}{l}\text { Browser } \\
\text { Scre-en }\end{array}$ & Get & Button & $\begin{array}{l}\text { getActionP } \\
\text { erformed() }\end{array}$ & $\begin{array}{l}\text { It makes } \\
\text { changes to } \\
\text { the page } \\
\text { according } \\
\text { to the } \\
\text { changes } \\
\text { saved } \\
\text { upto the } \\
\text { user's last } \\
\text { visit to } \\
\text { this page }\end{array}$ \\
\hline
\end{tabular}

Three levels of user interface are provided separately. The first is a very simple browser with five buttons, "Back, "Forward", "Home", "Bookmarks", "Exit". The second level has personalization features like "Highlighting", "Removal of Text/Components" and "Addition of Text/Components" in a Web Page. The third level has one more "History" function added to the second level user interface to facilitate the user for retrieving the browsing history. The prototype was tested by several users with different needs. The feedbacks from these users show that simplicity is very important for inexperienced users. The first level user interface is adequate for user who is not experienced with using computers. The second level user interface is necessary for user who has already known how to surf the Web and uses the web frequently. The user personalization feature of this level helps the user to interact more effectively with the World Wide Web. However, there is no positive feedback for the third level interface. In other words, the users seem to seldom use the "History" function. One reason for the neglecting of this function can be due to the fact that none of the user has used the browser enough long time. A promising conclusion through observation is that changing user interface with relative consistency seems to have no obvious negative effect.

\section{DISCUSSION AND FUTURE WORK}

User adaptation has merits for personalizing the application. In the meantime, it raises questions such as how to keep consistency while changing the interface layout by dynamically adding functions, and how to balance between user control and the automation of the agent. Our observation is that the dynamism can have positive effect happening when it is required. A proper algorithms on adaptation based on the general user model can be of value. To obtain this model, a proxy server can be utilized to $\log$ and analyse the users' interactions. Our future work will concentrate on adaptation of the browser based on the user's usage model and general user model with the active participations of the end users.

\section{REFERENCES}

[1] Beth Meyer, Richard A. Sit, Victoria A. Spaulding, Sherry E. Mead, Neff Walker. Age Group Differences in World Wide Web Navigation. CHI 97 Electronic Publications: LateBreaking/Short Talks. Available at http://www.acm.org/sigchi/chi97/proceedings/short-talk/ bm.htm.

[2] [Williamson 96] Kirsty Williamson, Amanda Bow, Karen Wale. Older People, New Technology, and Public Libraries. Paper presented at Reading the Future. Biennial Conference of the Australian Library and Information Association, 1996.

[3] Y. Zhao, E. Tyugu, D.Sidarkeviciute, First Solutions to Intelligent Personal Assistants for Senior Citizens. Technical Report TRITA-IT R 97:25, Dept. of Teleinformatics, KTH, Stockholm, 1997.

[4] Paul P. Maglio, Teenie Matlock. Metaphors We Surf the Web By. To appear in Workshop on Personalized and Social Navigation in Information Space, Stockholm, Sweden, 1998.

[5] David Abrams, Ron Baecker. How People Use WWW Bookmarks. CHI 97 Electronic Publications: LateBreaking/Short Talks. Available at http://www.acm.org/sigchi/chi97/ proceedings/shorttalk/da.htm.

[6] Barrett, R., Maglio, P. P. \& Kellem, D. C. WBI: A Confederation of Agents that Personalize the Web. In Proceedings of the First International Conference on Autonomous Agents. New York, NY: ACM Press, 1997.

[7] Paul P. Maglio, Rob Barrett. How to Build Modeling Agents to Support Web Searchers. In Proceedings of the Sixth International Conference on User Modeling. New York, NY: Springer Wien, 1997.

[8] Christoph G. Thomas, Gerhard Fischer. Using Agents to Improve the Usability and Usefulness of the World-Wide Web. In: Proceedings of the Fifth International Conference in User Modeling (UM-96). West Newton: User Modeling, 1996. S. 5-12.

[9] Thomas, Christoph; Fischer, Gerhard. Using agents to personalize the Web. In: Moore, J.; Edmonds, E.; Puerta, A. (Hrsg.): Proceedings IUI'97 - International Conference on Intelligent User Interfaces. New York: ACM, 1997.

[10] Alfred Kobsa. User Modeling: Recent Work, Prospects and Hazards. Appeared in M. Schneider-Hufschmidt, T. K•hme and U. Malinowski, eds. Adaptive User Interfaces: Principles and Practice. North-Holland 1993. Available at http://zeus.gmd.de/ kobsa/papers/193-aui-kobsa.ps.

[11] Fink, Josef; Kobsa, Alfred; Nill, Andreas. Adaptable and Adaptive Information Access for All Users, Including the Disabled and the Elderly. The Sixth International Conference on User Modeling, Chia Laguna (Sardinia/Italy) Springer Wien New York 1997. 
[12] Wilbert O. Galitz. Essential Guide to User Interface Design. John Wiley \& Sons, Inc. pp.35-50, 1996. [Java] http://java.sun.com.

[13] FIPA98 Draft Specification: Part 8 Human Agent Interaction. Available at http:// www.networking.ibm.com/iag/iagfipa8713.html.

[14] Paul P. Maglio, Rob Barrett. On the Trail of Information Searchers. In Proceedings of the Nineteenth Annual
Conference of the Cognitive Science Society. Mahwah, NJ: Lawrence Erlbaum, 1997.

[15] M. Helander (ed.) Handbook of Human-Computer Interaction. Elsevier Science Publishers B.V. (NorthHolland), pp.581-598, 1988 